\title{
Howard Hughes Institute and tax collectors bury the hatchet
}

\section{Washington}

THE Trustees of the Howard Hughes Medical Institute have agreed to pay $\$ 35$ million in back taxes without protest as part of the settlement of a long-standing dispute with the Internal Revenue Service (IRS) over Hughes' tax status.

In addition to the $\$ 35$ million, to be paid by the end of this fiscal year, Hughes has agreed to spend $\$ 500$ million over and above the minimum amount required to preserve its status as a medical research organization (MRO).

Hughes and the IRS have debated for some time exactly what MRO status means. Established in the 1950 tax code, MROs must be involved in "direct conduct of research in conjunction with hospitals", a phrase Hughes president Donald
Fredrickson says has been studied "with Talmudic discipline". Very few foundations in the United States have chosen to use the MRO classification, certainly none with endowments approaching the $\$ 5,000$ million of Hughes, so the rules were not clear. Fredrickson says the nature of biomedical research has shifted since 1950. Much important biomedical research is being conducted at institutions not connected with hospitals.

Hughes was anxious for the flexibility to become involved in areas not so tightly tied to clinical research. The settlement with IRS appears to make that possible. Joseph Perpich will join Hughes on 15 April to direct a new programme that will take Hughes activities into new areas of making grants and offering fellowships.

\section{Sizewell B reactor gains expected approval from UK government}

\section{London}

PredictabLy, the British government has given official approval to the construction of a $£ 1,500$-million pressurized-water reactor (PWR) at Sizewell on the Suffolk coast. The station, which will join a gascooled nuclear reactor on the same site, will be the first of five nuclear complexes, costing $£ 6,000$ million in total, installed around the United Kingdom.

The approval met criticism from both opposition parties; they raised doubts about the safety aspects of the PWR in the wake of Chernobyl, and the economic case for the reactor in the light of current fuel prices.

The Energy Secretary, Mr Peter Walker, was undeterred. He concluded that "there is good confidence that Sizewell $B$ is sufficiently safe to be tolerable and that the national need for the station overrides the local interest in favour of conservation".

The reactor has been the subject of much public debate since it was first suggested in the late 1970s. A public inquiry was held between January 1983 and March 1985 from which Sir Frank Layfield, the chairman, was able to produce a report published in January of this year.

The Layfield study recommended approval, although it conceded that comprehensive tests on the safety of the design could not be carried out at this stage. The opponents of the PWR called for better assurances and claimed that the report was irrelevant because it took no account of the accident at Chernobyl.

Walker was adamant that the programme will go ahead. He said: "The
PWR design for Sizewell B is of a different reactor type from the Soviet RBMK design (Chernobyl). All nuclear power stations in the UK, unlike those in the USSR, must have engineered control and automatic protection systems. Moreover, our system of regulation, unlike that

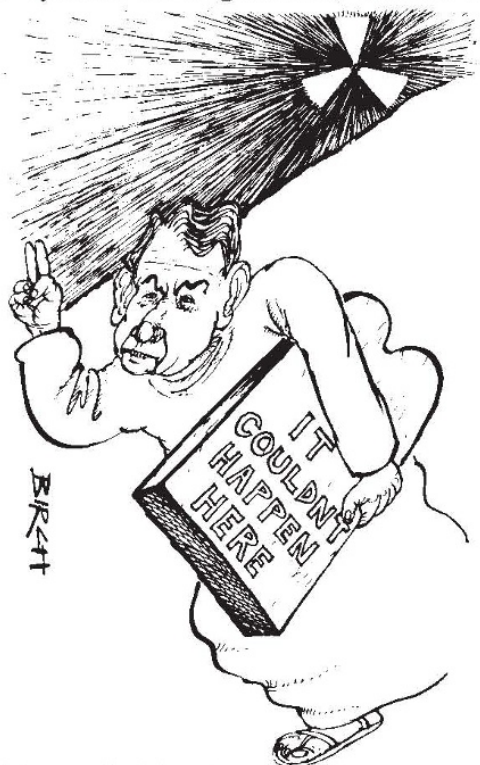

which applied in the USSR, ensures that there is a proper and reliable procedural framework of controls."

The experience of the United Kingdom, he continued, demonstrated that "there is a superior safety culture" to that at Chernobyl. Many of the conservationists who gave evidence against Sizewell B do not share the minister's view and plan a public rally, to be staged in London, to protest at the government's decision. Bill Johnstone

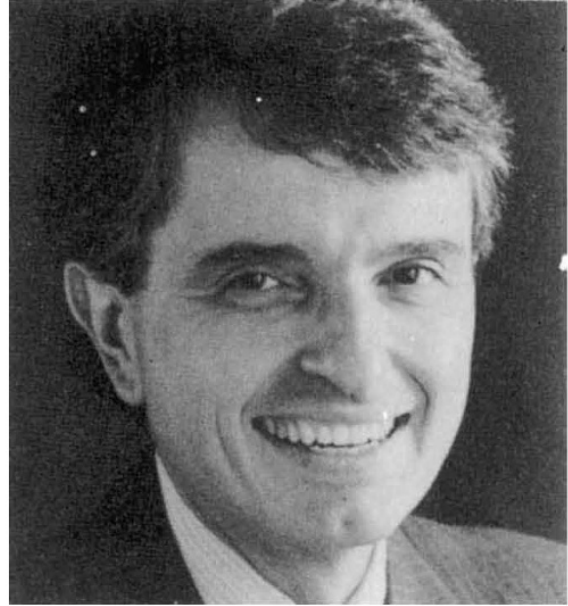

Perpich-expanding Hughes' horizons.

George Thorn, former president of the Hughes Institute and now chairman of the board of trustees, says the major emphasis will be on education. A preliminary meeting to discuss how much money is available and how it will be spent was scheduled for earlier this week in Washington.

Losing MRO status would have meant becoming a private foundation, something the institute was anxious to avoid. Foundations must adhere to more complicated rules in distributing money, and are more restricted in the type of assets they may possess, says Thorn. Private foundations must also spend 5 per cent of their endowment annually, as opposed to the 3.5 per cent required of MROs. Fredrickson says reverting to being a foundation would have required massive organizational changes in the structure of the 24 facilities the institute operates and the 1,000 people it employs. Estimating tax penalties for failing to achieve MRO status had also loomed as a potential nightmare.

Private foundations have, however, been able to survive under IRS rules. Richard Lyman, president of the Rockefeller Foundation, says he regards the 5 per cent spending figure as reasonable. Favourable economic conditions have permitted Rockefeller's endowment to grow from $\$ 1,200$ million to $\$ 1,800$ million this year.

The Hughes Institute's fortunes changed dramatically with the sale in 1985 of the Hughes Aircraft Company to General Motors. That sale provided the bulk of the institute's endowment, and transformed it into a major force among private philanthropies. In addition to the medical institutes it operates, and the new grantgiving endeavour, the Hughes Institute is also supporting a major effort to establish a database for human genetic information at Yale University. This new database may become the de facto standard for information collected by a project to sequence the entire human genome now being considered by several countries.

Joseph Palca 